\title{
SAR Pancake Ice Thickness Retrieval in the Terra Nova Bay (Antarctica) during the PIPERS Expedition in Winter 2017
}

\author{
Giuseppe Aulicino ${ }^{1,2, *(\mathbb{D}}$, Peter Wadhams ${ }^{1}$ and Flavio Parmiggiani ${ }^{3}(\mathbb{C}$ \\ 1 Department of Life and Environmental Sciences-DiSVA, Università Politecnica delle Marche, \\ Via Brecce Bianche, 60131 Ancona, Italy; pw11@cam.ac.uk \\ 2 Department of Science and Technology_DiST, Università degli Studi di Napoli Parthenope, \\ Centro Direzionale Is C4, 80143 Napoli, Italy \\ 3 Department of Satellite Meteorology, ISAC-CNR, Via Piero Gobetti 101, 40129, Bologna, Italy; \\ f.parmiggiani@isac.cnr.it \\ * Correspondence: g.aulicino@staff.univpm.it
}

Received: 26 September 2019; Accepted: 24 October 2019; Published: 26 October 2019

\begin{abstract}
Pancake and frazil ice represent an important component of the Arctic and Antarctic cryosphere, especially in marginal ice zones. The retrieval of their thickness by remote sensing is, in general, a difficult task. A processing system was developed and refined by the present authors in the framework of the EU SPICES project; it is meant for routinely deriving ice thickness in frazil-pancake regions using the spectral changes in wave spectra from imagery provided by space-borne Synthetic Aperture Radar (SAR) systems. This methodology was successfully tested in the Beaufort Sea through comparison with ground truth collected during the cruise of the "Sikuliaq" in the fall of 2015. In the present study, this technique has been adapted and applied to Antarctic frazil/pancake icefields using COSMO-SkyMed satellite images. Our retrievals were analyzed and validated through a comparison with co-located in situ observations collected during the 2017 PIPERS cruise in Terra Nova Bay polynya. A broad agreement was found between measured thicknesses and those retrieved from the SAR analysis. Results and statistics presented and discussed in detail in this study represent a step towards the autonomous measurement of pancake icefields in remote areas such as Antarctic coastal polynyas and marginal ice zones.
\end{abstract}

Keywords: pancake ice; ice thickness; SAR; Terra Nova Bay polynya; PIPERS cruise

\section{Introduction}

The presence and evolution of sea ice cover determine several basic characteristics of the polar regions, affecting the exchange of heat, energy, mass, and momentum between the ocean and the atmosphere as one of the largest seasonal changes on the planet [1,2]. The recent dramatic reversal in the changes occurring in the Antarctic sea ice, i.e., from relatively gradual increases to rapid decreases [3], emphasizes the urgency of improving our capability to monitor its formation and evolution.

Frazil and pancake ice represent the initial phase of sea ice cover formation before congelation into pack ice, and can be considered the main ice types where polynyas form. The heat and salt fluxes associated with their formation assist convection processes and can modulate the vigor of the overturning processes, so their role in the planetary energy system is extremely important $[2,4]$. The growth rate of a pancake ice cover is elevated compared to a continuous ice sheet, and the ice is more dynamic [5]. The presence and attenuation of waves that enter the ice from open water are the leading factors that determine the extent of the pancake zone and thus the total area over which elevated ice production rates occur [1]. In fact, pancake ice forms when seawater freezes in turbulent 
conditions, such as an open ocean with a wave field [2]. In these conditions small crystals of frazil ice crowd together and freeze to form small circular cakes; wave action prevents them from creating a continuous ice cover causing collisions, which maintain the cakes as separate entities and raise their rims to obtain the typical resemblance to pancakes. These cakes usually appear temporarily at an advancing ice edge reaching a thickness of only a few tens of $\mathrm{cm}$ and diameters of 1-3 $\mathrm{m}$, which depends on the high-frequency part of the wave spectrum [6]. Nevertheless, under strong and constant wave conditions, the frazil layer can develop to a considerable thickness (up to $75 \mathrm{~cm}$ ) with eventual diameters of up to $5 \mathrm{~m}[7]$.

Once the incoming wave energy has decayed sufficiently, pancakes freeze together, with the frazil acting as the adhesive, to form an extensive ice sheet. The exact distance from the ice edge before pancakes freeze together varies depending on the incoming wave spectra. However, if the penetrating wave energy increases again, the newly formed ice sheet may break into floes, the size of which will be determined by the incoming wave spectra [8]. A combination of smashed floes of varying sizes and newly formed frazil appears between floes. When the wave energy decreases again, this mixture freezes together with the floes to form a new ice sheet. This process can occur repeatedly during freeze-up with an associated high salt flux that gives frazil-pancake ice significant geophysical and climatic importance assisting convection and the critical growth cycle which drives the annual mass budget of the sea ice [4].

This process usually takes place over the outer part of the advancing Antarctic ice cover in winter [9] but pancake is also the main ice type where coastal polynyas are kept open by prevailing offshore winds (e.g., [10]). This makes polynyas ice-production factories, regarded as important places for deep-water formation and ventilation of the ocean in the Antarctic [11,12] and along certain Arctic coasts [2]. One of these hot spots is the Terra Nova Bay (TNB) coastal polynya [13] that is generated and maintained by persistent katabatic winds in the western sector of the Ross Sea. Their action advects newly formed pancake ice far from the coast, preventing its consolidation into thick pack ice and facilitating the continuous formation of new frazil and pancake ice [4].

Several efforts have been made to develop an image processing scheme for the automatic measurement of pancake ice size distribution from airborne and satellite acquisitions (e.g., [14,15]), but the remote retrieval of its thickness still remains a challenge. The aim of this study is to move a step towards routine satellite estimation of pancake ice thickness in these remote areas. A processing system to retrieve pancake icefield thickness was previously developed and refined by Wadhams et al. [2] using the spectral changes in wave spectra from imagery provided by space-borne Synthetic Aperture Radar (SAR) systems. This methodology was successfully tested in the Arctic ocean through comparison with ground truth collected in the Beaufort Sea during the cruise of the "Sikuliaq" in the fall of 2015.

In the present study, the technique was adapted to the Antarctic region and applied to an interesting case study observed during the 2017 "Polynyas, Ice Production, and Seasonal Evolution in the Ross Sea" (PIPERS) project cruise in the TNB, Ross Sea, Antarctica (Figure 1). It represents the first application of this technique to estimate pancake ice thickness produced in Antarctic coastal polynyas from COSMO-SkyMed (CSK) SAR images. A complete description of datasets and methodology is provided in Section 2. Results and discussion are presented in Section 3. Conclusions are reported in Section 4. 


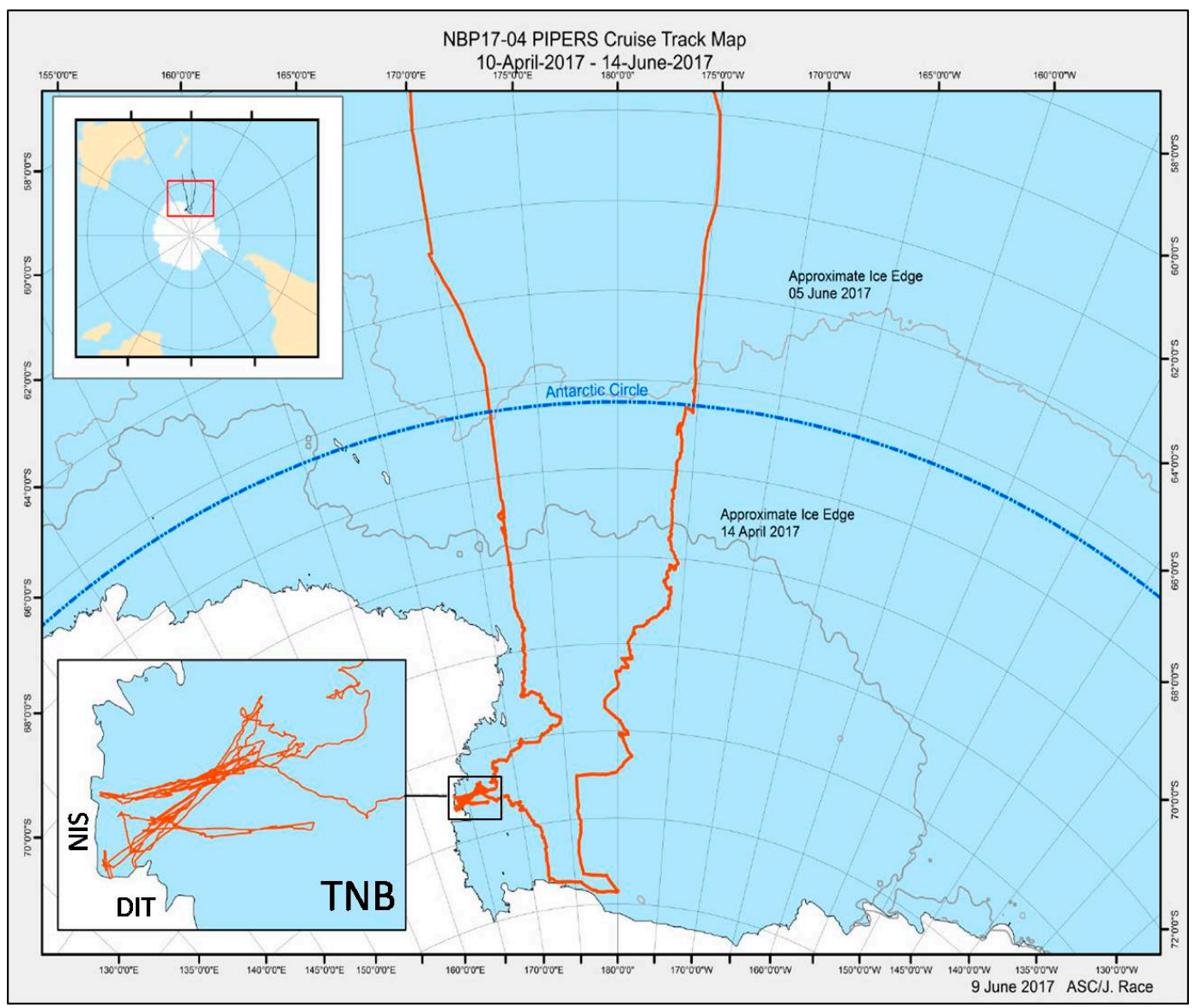

Figure 1. PIPERS cruise track map in the Ross Sea. Courtesy of the University of Texas at San Antonio (http://www.utsa.edu/signl/PIPERS/gallery.html). A stereographic map of Antarctica (top-left box) and a zoom on the Terra Nova Bay (TNB) study area (bottom-left box) are also presented. NIS and DIT acronyms identify Nansen Ice Shelf and Drygalski Ice Tongue, respectively.

\section{Data and Methods}

\subsection{Synthetic Aperture Radar Dataset}

A basic requirement for testing our methodology across an Antarctic polynya was the availability of SAR imagery in conjunction with in situ pancake ice observations. To this aim, we took advantage of the X-band CSK SAR products acquired by the Italian Space Agency (ASI) during the 2017 PIPERS winter cruise in the western Ross Sea. The X-band images are acquired in ScanSAR Wide mode, with the Level 1B Ground Range resolution being $30 \mathrm{~m}$.

Thanks to their revisit capability (i.e., up to 16 acquisitions/day over a specific target at $70^{\circ} \mathrm{S}$ latitude) and space resolution $(<25 \mathrm{~m})$ CSK SAR products are suitable for ice floe detection and tracking, ice feature estimation and waves-in-ice retrieval.

As previously demonstrated by Wadhams et al. [2], other SAR imagery may also be appropriate for this purpose (e.g., Sentinel-1 and TerraSAR-X). Nevertheless, during this experiment no useful images could be obtained from other satellites with the correct location and timing needed for direct comparison with ground truth. Conversely, dedicated acquisitions of CSK images were planned and ordered for exactly the area and date of PIPERS crossing the TNB polynya in order to support the field activities. Among these observations, we opted to use the CSK SAR-X HH-polarized images collected on 6 May, 10 May and 12 May 2017 over the study area (Figure 2). The choice of HH polarization, essentially based on previous experiences of the authors (e.g., [2]), has proved to be the most efficient for discriminating thinner first year ice types in these kind of images. 

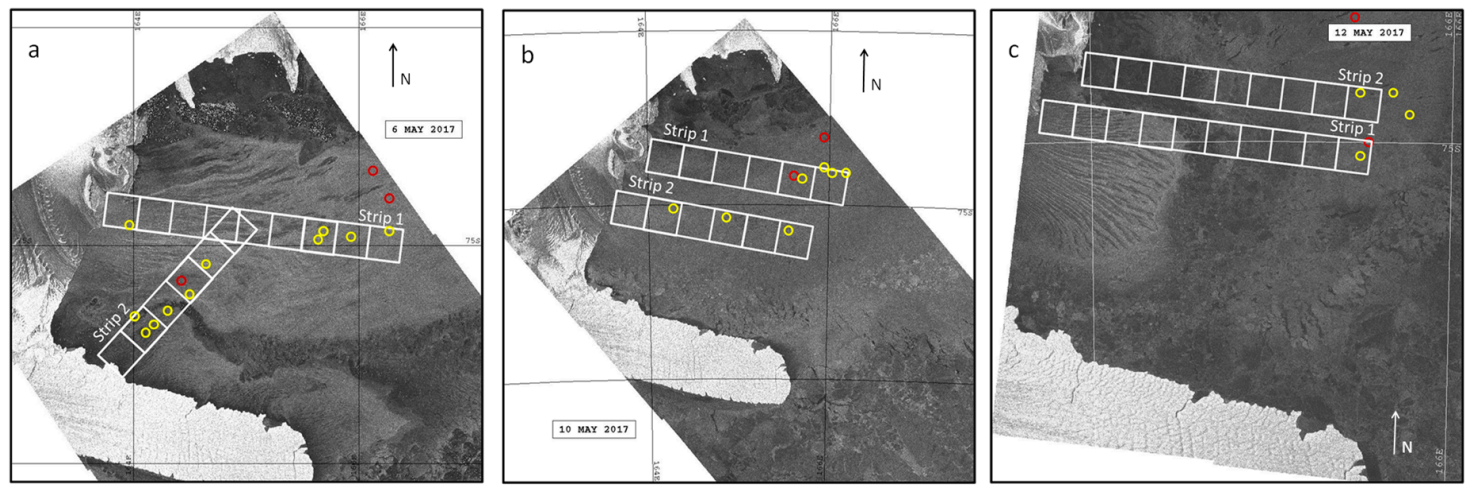

Figure 2. Terra Nova Bay seen from CSK SAR-X on (a) 6 May 2017 03:06:45 UTC; (b) 10 May 2017 03:30:40 UTC; (c) 12 May 2017 06:31:28 UTC. The locations of the stripmaps in the imagettes, as well as PIPERS ice core (red circles) and visual observations (yellow circles) sites, are reported in white.

\subsection{The Use of SAR to Retrieve Pancake Ice Thickness}

Previous studies demonstrated that wave parameters (i.e., wavelength, wave direction and wave height) can be derived from directional ocean wave spectra, which reflect the distribution of wave energy in wave number and propagation direction [16-22]. Although ocean wave spectra can be retrieved from real SAR imagery, the use of cross spectra methods involving a SAR complex component [23] gives the advantages of better speckle noise suppression and easier $180^{\circ}$ ambiguity removal from retrieved spectra.

The analysis of the SAR images followed the procedure described in Wadhams et al. [2]. Two separate strips of several imagettes (i.e., subscenes of $7.68 \times 7.68 \mathrm{~km}, 512 \times 512$ pixels) were extracted from each SAR scene near the ship positions following the main direction of the incoming waves. Their locations were defined in order to cross the ice/sea edge and cover the sites of the field pancake measurements.

For each imagette the SAR spectrum was then computed, providing input to the following SAR/wave spectrum inversion step. This analysis followed the procedure described in Wadhams et al. [16-18], taking advantage of ESA-NEST, TerraScan, and MATLAB software packages and the RSI Interactive Data Language. Based on the Hasselmann and Hasselmann [19] non-linear integral transform, as improved in [20], for open water windows the procedure first estimates the wind-sea spectrum according to the parametrization derived in $[21,22]$. The wind speed values measured aboard the PIPERS cruise during the field experiments were used to compute the wave age value that minimizes the difference between the observed and simulated SAR spectra. To this end, the SAR image was used for the preliminary estimation of the real aperture radar (RAR) modulation transfer function (MTF). This inversion scheme involves the minimization of a properly defined cost function, which uses the observed SAR spectrum (computed by fast Fourier transform), the first guess ocean directional wave spectrum and the best fit ocean wave spectrum. Details, constants and possible issues are reported and discussed by Wadhams et al. [2], see Appendix A.

For pancake ice subscenes, a wave propagation model for wave dispersion and attenuation, following the Keller theory [24], was used to invert the SAR spectra and parametrically infer physical properties such as pancake thickness and the wave attenuation rate. This model treats the ice layer as a viscous fluid, while the water beneath it is assumed inviscid. Considering that each component of the wave spectrum is attenuated when entering the icefield, this iterative procedure looks for the best sea ice thickness and sea ice viscosity values which minimize the difference between the observed and simulated SAR spectra (see Appendix B in Wadhams et al. [2]). The input parameters are the wave spectral density in open water, the attenuation rate computed by the mode and the distance traveled by the wave (from the ice edge to the center of the sea ice imagettes). The parametric inversion, using the RAR MTF value retrieved in the open sea region, allows us to retrieve both thickness and kinematic viscosity at a given distance from the ice edge. 
Please note that this procedure works properly only when dealing with thin sea ice (e.g., frazil, pancake). In fact, we assume that energy is transmitted without loss when the waves imaged by SAR cross the ice edge. As discussed below, this explains why this methodology does not provide reliable results when applied to thicker ice types.

\subsection{PIPERS In Situ Observations}

The PIPERS project is based on an interdisciplinary multiplatform field campaign to provide, for the first time, measurements of the local and large-scale controls on sea ice production in the western Ross Sea (http://www.utsa.edu/signl/PIPERS/). The cruise aboard the US icebreaker "Nathaniel B. Palmer" took place between April 11 and June 142017 (Figure 1) and aimed at monitoring the space/time evolution of air-ice-ocean interactions initiated during autumn and tracked into winter-spring in the western Ross Sea, with the specific objectives of measuring the atmospheric and oceanic heat balance at the surface. The analysis was carried out by: (i) determining the effect of katabatic wind surges on warming and sea ice growth; (ii) observing ocean property changes affecting sensible heat loss and water mass transformation; and (iii) measuring sea ice growth and thickness evolution and upper ocean properties.

Among the collected observations, this study includes sea ice thickness measurements co-located with the acquired CSK satellite images, extracted from two datasets: (i) the pancake ice cores collected in and around TNB by the Belgian team led by Jean-Louis Tison; and (ii) the underway pancake ice visual observations collected hourly from the bridge, covering the immediate vicinity of the ship (within $1 \mathrm{~km}$ radius) following the Antarctic Seaice Processes \& Climate (ASPeCt) protocol [25]. Both datasets were carefully analyzed before being used for comparison purposes.

The ice core thickness data present a limited number of measurements which are reasonable for co-located comparison with information retrieved from CSK SAR observations (red circles in Figure 2). Some of them were pretty far into the consolidated ice and there were no waves. Thus, we selected for direct comparison only the measurements clearly indicating thin/thick pancake ice in the core station description. Nevertheless, we noticed that the consolidated ice was pretty much entirely frazil even to the east of TNB, so that, even if there was some rafting, it still represents a good estimate of original pancake thickness.

ASPeCt underway data consist of about 270 visual observations collected across the TNB, reporting: detailed coded information on the three dominant ice types present in the pack (primary indicates the thickest, tertiary the thinnest); their partial concentrations; the mean thickness of the ice; the floe size; the presence/depth of snow cover; the topography and the open water fraction. The sea ice concentrations are given in 10\% intervals; the sea ice thickness is given in $10 \mathrm{~cm}$ intervals, unless the sea ice is thinner than $20 \mathrm{~cm}$, when the accuracy is $2-5 \mathrm{~cm}$.

Among these measurements, we selected only those co-located at space/time with the acquired CSK SAR images, reporting the presence of level ice, rafted pancakes and/or cemented pancakes (yellow circles in Figure 2). While there were many pancakes during the period at which we are interested (6-12 May), they were often mixed in with other ice types (usually frazil) and/or consolidated in sheet ice (which had obviously only recently been pancake ice). This information was carefully considered when making the comparisons discussed in the following section.

\section{Results and Discussion}

The high resolution CSK SAR images in Figure 2 allow for the visual identification of both the polynya opening and the possible presence of frazil/pancake ice, distinguishing them from offshore uniform consolidated pack ice. Long and wide streaks of pancake ice, formed from the lateral growth of frazil ice through the Langmuir circulation, are present in Figure 2a,c. This circulation is a turbulent process driven by wind and waves that appears in the upper layers of large bodies of water affecting dispersion as well as production and maintenance of the surface mixed layer and the pycnocline [26]. The separation scales and lengths of Langmuir cells generally increase with wind speed and distance 
from the coast $[27,28]$, but there are also clear deviations from this relationship. In fact, the Langmuir circulation does not only depend on wind stress but also on the Stokes drift, the average velocity of a fluid parcel, and of surface waves [29].

Although it is still under discussion whether their formation is solely a result of upper-ocean turbulence or whether the ice itself affects the turbulence reinforcing streak formation, we know that pancake development is enhanced by a dampened wave field within the wider streaks. Despite the absence of katabatic events, and of consequent Langmuir streaks, a uniform area of pancake ice was detectable also on 10 May (Figure 2b).

These processes are driven by sustained katabatic winds, blowing from the Nansen Ice Sheet on 6 and 12 May, which usually force the opening of the coastal polynya and the downstream advection of newly formed pancake ice $[4,10]$. The pancakes, typically grouped as small floes with limited diameters [30], are then pushed out creating a wide area of rafted accumulated floes, with an estimated thickness of 30-40 cm during PIPERS field operations.

When katabatic forcing halts, pancake advection slows down favoring the floes' cementation and a progressive polynya freeze up to create a uniform cemented pancake icefield (e.g., on 10 May-Figure 2b).

In general, the pancake ice gives a dark return on SAR imagery because of the way in which it damps out very short (a few cm wavelength) ripples at the Bragg wavelengths, but it still permits longer ocean waves to show through and thus be detectable in spectral analysis [2]. The change in the shape of the spectrum when the waves enter the ice is usually very clear, the same for the presence of mixed sea ice types.

An example is provided by wave spectra of the imagettes extracted from 6 May CSK SAR acquisition (Figure 3): the first imagette (from left) represents ocean surface water kept open by intense katabatic winds, while the second to seventh windows identify pancake ice; mixed ice types are instead visible in the last two windows.

From these data, a pancake ice thickness ranging between $5.5 \mathrm{~cm}$ (imagette 2) and $10.0 \mathrm{~cm}$ (imagette 5-7) was retrieved through the inversion technique described in the previous section. Mixed ice types were identified in the last subscenes, so that it was not possible to estimate reliable ice thickness there due to the absence of a homogeneous frazil-pancake icefield. These results agree well with in situ visual observations collected during PIPERS field activities (yellow circles in Figure 2a) which report a mean pancake thickness of $5 \mathrm{~cm}$ (imagette 1) and $11 \mathrm{~cm}$ (imagette 7). Similar thicknesses were retrieved across the second stripmap that was extracted from the 6 May CSK SAR image, i.e., the one covering the polynya area which opened offshore from the western sector of the Drygalski Ice Tongue. Here the pancake mean thickness ranged between 5.3 (imagette 1) and $7.4 \mathrm{~cm}$ (imagette 3) with different ice types in the last subscenes. Again, PIPERS visual observations report a mean value of $7.1 \mathrm{~cm}$ in the analyzed pancake windows (imagettes 1 to 3 ). Figure 4 presents a comparison between retrieved estimations and co-located in situ observations through the scatterplot of SAR and ASPeCt thicknesses collected during this first experiment (red circles). Despite the limits of the low-resolved in situ samples and the reduced number of available co-locations, these results suggest the applicability of the presented methodology to the polynya area. 


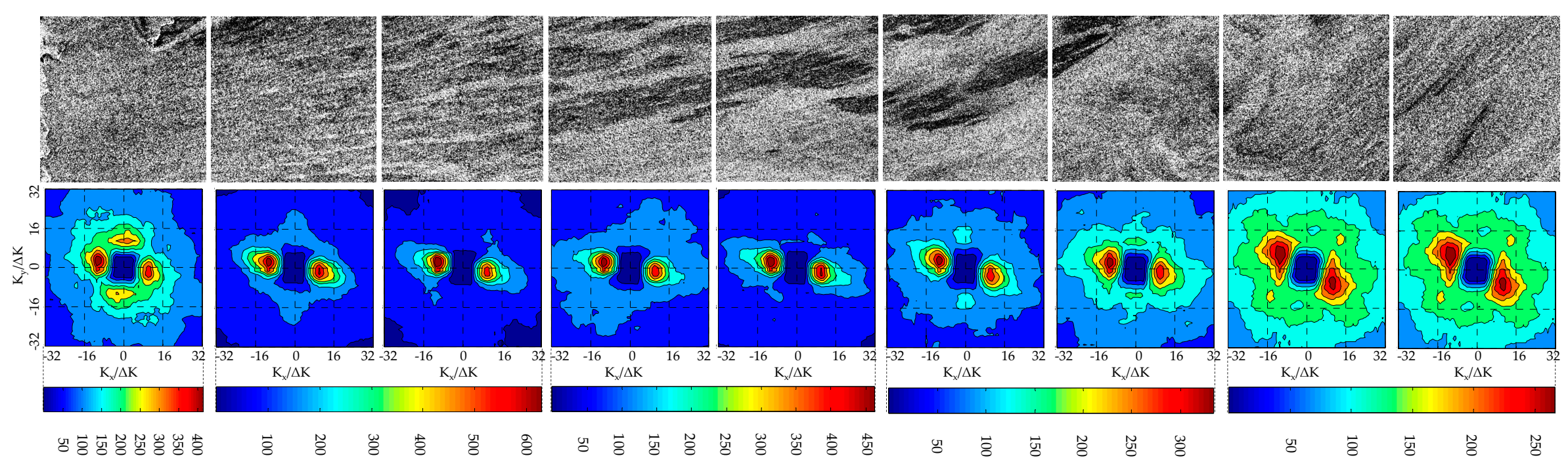

Figure 3. Observed SAR spectra for stripmap 1 imagettes extracted from 6 May 2017 CSK SAR-X acquisition. Units are wavenumbers $\mathrm{Kx} / \Delta \mathrm{K}$ and $\mathrm{Ky} / \Delta \mathrm{K}$, with $\Delta \mathrm{K}=$ $\pi / 810^{-2} \mathrm{rad} \mathrm{m}^{-1}$. The top of the spectra is not due north but in the direction of right angles to the incoming main wave vector. 


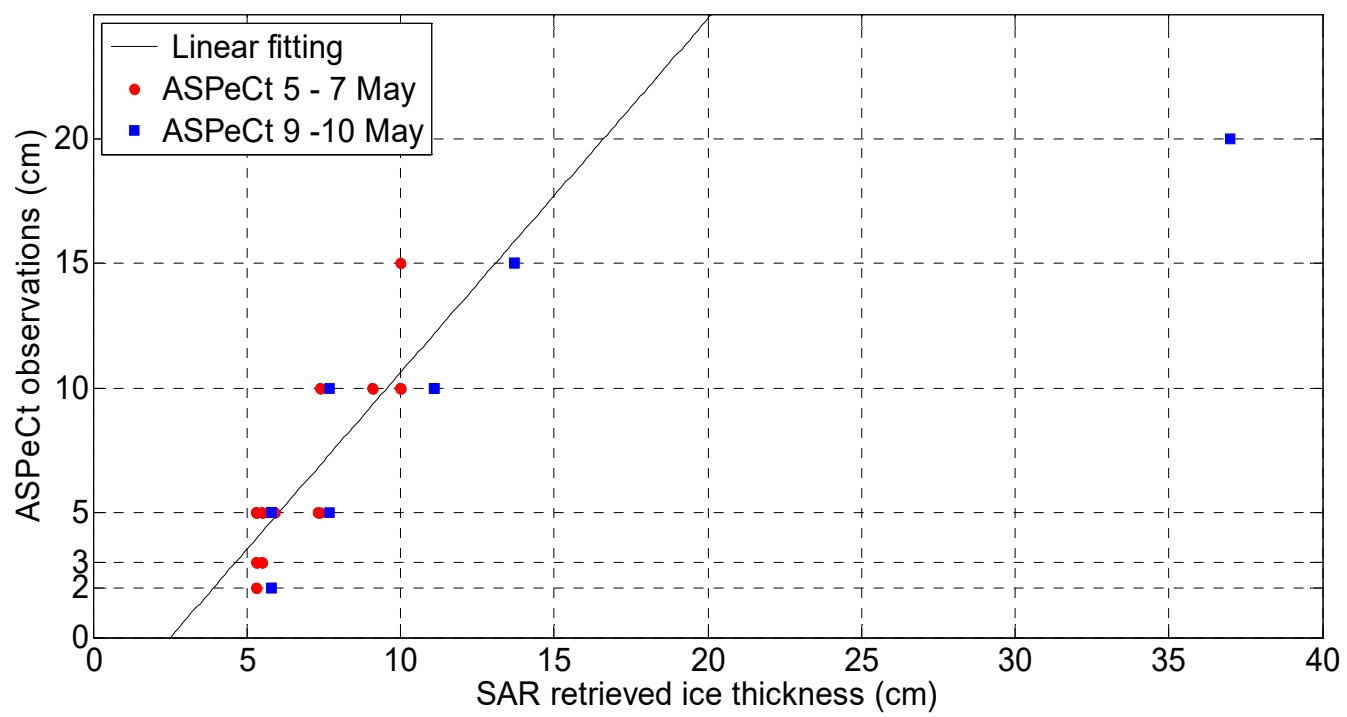

Figure 4. Scatterplot of SAR retrieved and ASPeCt in situ pancake ice thicknesses co-located in space and time, collected during the 6 May (red circles) and 10 May (blue squares) experiments. Linear fitting between observed and retrieved data (black line) does not include the value on the top right of the figure which does not represent pancake ice.

A second case study took advantage of the CSK SAR image acquired on 10 May (Figure 2b). Two parallel stripmaps were extracted along the main wave direction. As for the first stripmap, the presence of thin pancake ice was identified in the imagettes 1 to 4 pointing to a mean thickness of $11.2 \mathrm{~cm}$; unfortunately, no co-located in situ observations are available for direct comparison with this result. SAR spectra derived from the second stripmap showed the presence of pancake ice in the first three imagettes. PIPERS scientists confirmed that the consolidated ice was largely pancake even to the east, though some rafting was present. In situ data suggest that pancakes tended to be about $5 \mathrm{~cm}$ thick closer to the coast, and 10-15 cm to the east with some rafting up to $20 \mathrm{~cm}$ (Figure 5). A very good agreement was found for both imagette 2 (retrieved $5.8 \mathrm{~cm}$-observed $5.0 \mathrm{~cm}$ ) and imagette 4 (retrieved $11.1 \mathrm{~cm}$-observed $10 \mathrm{~cm}$ ). Although some correspondence can be found with ice cores (red circles in Figure 2) which report ice thickness up to $25 \mathrm{~cm}$, a lower agreement was found for imagette 6 (retrieved $37.3 \mathrm{~cm}$-observed $15 \mathrm{~cm}$ ) possibly due to the presence of mixed ice types. A direct comparison is provided in Figure 4 where the scatterplot of SAR and ASPeCt thicknesses collected during the second experiment is presented (blue squares). Again, despite the limits of the test datasets, these results are encouraging.

Finally, we analyzed a third SAR-X image, i.e., the one captured from the satellite on 12 May (Figure 2c). Two stripmaps were extracted from this acquisition, the first one placed inside the area of polynya, typically characterized by the presence of the Langmuir streaks, the other one in a zone of much more uniform ice conditions located on the northern edge of TNB. The application of the mentioned inversion technique allowed us to retrieve the presence of pancake ice (with a mean thickness of $10.6 \mathrm{~cm}$ ) only in the first three imagettes of the extracted stripmap. Although these results seem reliable, a direct comparison with co-located in situ observations was not possible because the PIPERS cruise was moving far from the TNB coast on that day.

These experiments confirm that our estimations well reproduce the ice thickness measured along the PIPERS cruise that, once it was consolidated, was generally about 10-20 cm thick. In particular, once fully formed, the pancakes tended to be about $5-10 \mathrm{~cm}$ thick closer to the coast, but often consolidated to the east (with some rafting) to about $20 \mathrm{~cm}$ thick (Figure 5).

These results confirm the general applicability of the methodology to the Terra Nova Bay polynya and the opportunity of realizing additional tests in coastal polynyas and other polar areas where pancake ice is usually observed. Nevertheless, as expected, the presented comparison between 
SAR derived and in situ thicknesses is less fascinating than the one reported by Wadhams et al. [2] through the application of the original algorithm in the Beaufort Sea marginal ice zone during the 2015 Sikuliaq scientific cruise. The different performances could be ascribed to several technical and geographical factors.

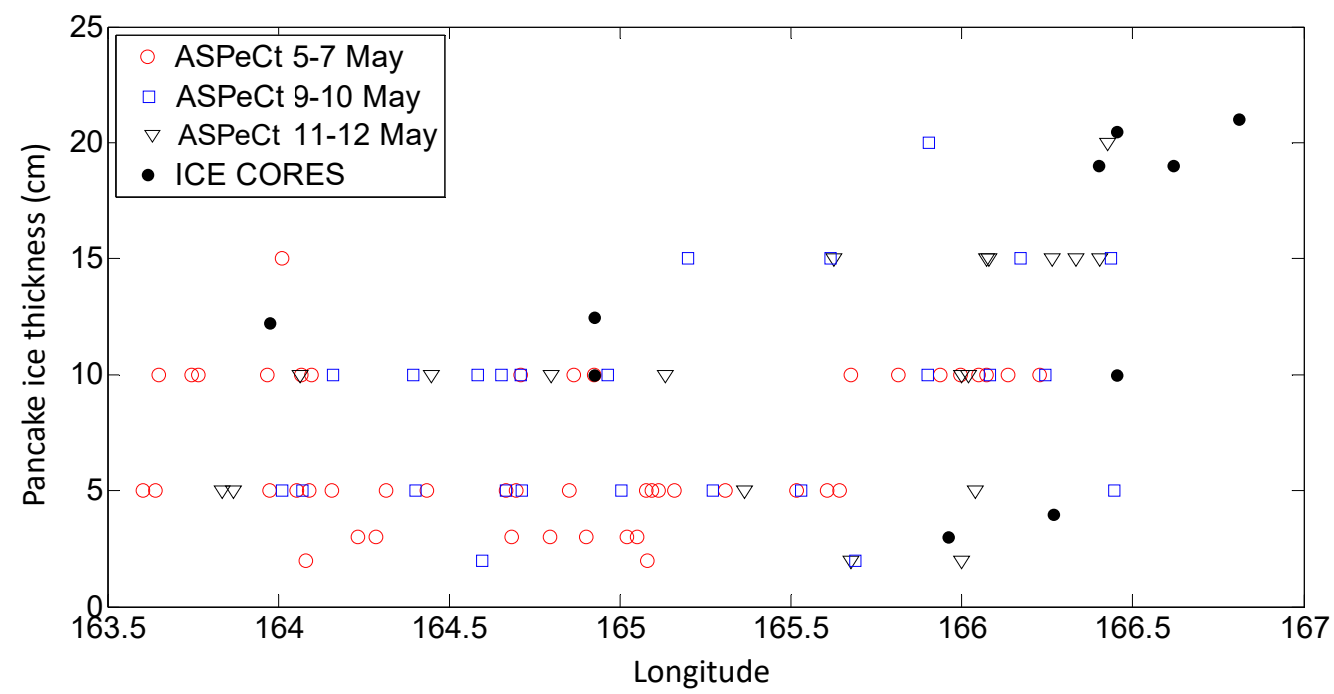

Figure 5. Terra Nova Bay in situ pancake ice thickness collected by PIPERS scientists through ASPeCt visual observations on 5-7 May (red circles), 9-10 May (blue squares), 11-12 May (black triangles); and ice cores (black dots).

First of all, the two studies apply the same methodology in geographical contexts characterized by considerably different dynamics and oceanographic conditions, i.e., a coastal polynya and an open ocean marginal ice zone. In particular, coastal polynyas are driven by peculiar wind regimes, the katabatic; the wind forcing directly enters the algorithm, so any inaccuracy on its value partially affects the accuracy of the pancake thickness estimation. In this sense, we look forward to having in a short while accurate wind field products routinely retrieved from SAR imagery.

Another remarkable difference between the two studies is related to the available field data. The accuracy of the ASPeCt visual observations, which represent the only ground truth in this study, is lower than that associated to the in situ information collected during the 2015 cruise in the Beaufort Sea, which included: (i) visual observations using the ASSIST protocol (equivalent to the ASPeCt one); (ii) the recovery of pancake samples from over the ship side; and (iii) a thermodynamic technique utilizing surface temperature and energy flux measurements from the ship for estimating the ice thickness continuously. The latter also consisted of a more copious amount of samples available for comparison and validation statistics.

Nevertheless, the positive results achieved during this first experiment in the Terra Nova Bay encourage the authors to find additional field opportunities for improving the technique and its validation in coastal polynyas and other polar areas where pancake ice forms.

\section{Conclusions}

The PIPERS winter cruise to the Ross Sea (May-June 2017), offered a very convenient opportunity for observing the properties and thicknesses of frazil-pancake ice types in an Antarctic polynya. The operational regions were overlaid by dedicated CSK SAR imagery, enabling us to test and apply a SAR-waves technique, first developed by Wadhams and Holt [31] and then improved by Wadhams et al. [2,17], for deriving the thickness of frazil-pancake icefields from changed wave dispersion.

A field validation study was carried using in situ sea ice observations collected during the PIPERS field activities. The results show a broad agreement between the observed thicknesses and those 
retrieved from the CSK SAR images. Despite this agreement, because of the limited number of co-located information, the results obtained in TNB polynya are less impressive than those achieved in the Beaufort Sea marginal ice zone by Wadhams et al. [2]. In any case, this study represents an important step towards the application of the presented technique for the systematic satellite retrieval of the pancake icefield thickness in the polar regions, especially in topic regions like polynyas, where the final goal is mass flux estimates from coherent icefields.

To this end, in future it is necessary: (i) to create further validation opportunities to collect more ground truth to test and refine this technique; and (ii) to improve the model for thickness dependent wave dispersion theory in pancake ice.

Author Contributions: All authors conceived of and designed the manuscript, and performed the experiments. G.A. and F.P. processed the satellite measurements. G.A. and P.W. inspected the in situ observations. All authors analyzed the results, contributed to writing and approved the final manuscript.

Funding: This work was carried out under the framework of the Sea Ice-Wave Interaction Monitoring for Marginal Ice NaviGation (SWIMMING) project of the Italian PNRA. P.W. also thanks the financial support from Università Politecnica delle Marche under "Progetti europei: Premialità e Compensi Incentivanti 2017".

Acknowledgments: The authors wish to thank the Italian Space Agency (ASI) for providing COSMO-SkyMed imagery through the "ASI COSMO-SkyMed Open Call for Science Program" (Proposal Id 217). We also acknowledge S. Ackley, T. Maksym and the PIPERS cruise science team, who provided us with the unique in situ observations dataset collected during the 2017 winter cruise in the Ross Sea, for testing our retrieval technique in the Terra Nova Bay.

Conflicts of Interest: The authors declare no conflict of interest.

\section{References}

1. Doble, M.; De Carolis, G.; Meylan, M.H.; Bidlot, J.R.; Wadhams, P. Relating wave attenuation to pancake ice thickness, using field measurements and model results. Geophys. Res. Lett. 2015, 42, 4473-4481. [CrossRef]

2. Wadhams, P.; Aulicino, G.; Parmiggiani, F.; Persson, P.O.G.; Holt, B. Pancake Ice Thickness Mapping in the Beaufort Sea from Wave Dispersion Observed in SAR Imagery. J. Geophys. Res. Oceans 2018, 123, 2213-2237. [CrossRef]

3. Parkinson, C. A 40-y record reveals gradual Antarctic sea ice increases followed by decreases at rates far exceeding the rates seen in the Arctic. Proc. Natl. Acad. Sci. USA 2019, 116, 14414-14423. [CrossRef] [PubMed]

4. Aulicino, G.; Sansiviero, M.; Paul, S.; Cesarano, C.; Fusco, G.; Wadhams, P.; Budillon, G. A New Approach for Monitoring the Terra Nova Bay Polynya through MODIS Ice Surface Temperature Imagery and Its Validation during 2010 and 2011 Winter Seasons. Remote Sens. 2018, 10, 366. [CrossRef]

5. Doble, M.J.; Wadhams, P. Dynamical contrasts between pancake and pack ice, investigated with a drifting buoy array. J. Geophys. Res. Oceans 2006, 111, C11. [CrossRef]

6. Leonard, G.H.; Shen, H.H.; Ackely, S.F. Dynamic growth of a pancake ice cover. In Ice in Surface Waters, Proceedings 14th IAHR Ice Symposium, Trondheim, Norway, 14-18 June 2020; Shen, H.T., Ed.; A.A. Balkema: Rotterdam, The Netherlands, 1999; Volume 2, pp. 891-896.

7. Wadhams, P.; Wilkinson, J.P. The physical properties of sea ice in the Odden ice tongue. Deep. Sea Res. Part II 1999, 46, 1275-1300. [CrossRef]

8. Squire, V.A. A fresh look at how ocean waves and sea ice interact. Philos. Trans. R. Soc. Math. Phys. Eng. 2019, 376, 20170342. [CrossRef]

9. Wadhams, P.; Lange, M.A.; Ackley, S.F. The Ice Thickness Distribution across the Atlantic Sector of the Antarctic Ocean in Midwinter. J. Geophys. Res. Oceans 1987, 92, 14535-14552. [CrossRef]

10. Sansiviero, M.; Morales Maqueda, M.; Fusco, G.; Aulicino, G.; Flocco, D.; Budillon, G. Modelling Sea Ice Formation in the Terra Nova Bay Polynya. J. Mar. Syst. 2017, 166, 4-25. [CrossRef]

11. Gordon, A.L.; Zambianchi, E.; Orsi, A.; Visbeck, M.; Giulivi, C.F.; Whitworth, T., III; Spezie, G. Energetic plumes over the western Ross Sea continental slope. Geophys. Res. Lett. 2004, 31, L21302. [CrossRef]

12. Jacobs, S.S. Bottom water production and its links with the thermohaline circulation. Antarct. Sci. 2004, 16, 427-437. [CrossRef] 
13. Budillon, G.; Spezie, G. Thermohaline structure and variability in the Terra Nova Bay polynya, Ross Sea. Antarct. Sci. 2000, 12, 493-508. [CrossRef]

14. Parmiggiani, F.; Moctezuma-Flores, M.; Wadhams, P.; Aulicino, G. Image processing for pancake ice detection and size distribution computation. Int. J. Remote Sens. 2018, 40, 3368-3383. [CrossRef]

15. Alberello, A.; Onorato, M.; Bennetts, L.; Vichi, M.; Eayrs, C.; MacHutchon, K.; Toffoli, A. Brief communication: Pancake ice floe size distribution during the winter expansion of the Antarctic marginal ice zone. Cryosphere 2019, 13, 41-48. [CrossRef]

16. Wadhams, P.; Parmiggiani, F.; de Carolis, G. The use of SAR to measure ocean wave dispersion in frazil-pancake icefields. J. Phys. Oceanogr. 2002, 32, 1721-1746. [CrossRef]

17. Wadhams, P.; Parmiggiani, F.; de Carolis, G.; Desiderio, D.; Doble, M.J. SAR imaging of wave dispersion in Antarctic pancake ice and its use in measuring ice thickness. Geophys. Res. Lett. 2004, 31, L15305. [CrossRef]

18. Wadhams, P.; Aulicino, G.; Parmiggiani, F.; Pignagnoli, L. Sea Ice Thickness Mapping in the Beaufort Sea Using Wave Dispersion in Pancake Ice-A Case Study with Intensive Ground Truth; ESA SP, SP-740; European Space Agency Special Publication: Paris, France, 2016.

19. Hasselmann, S.; Hasselmann, K. On the nonlinear mapping of an ocean wave spectrum into a synthetic aperture radar image spectrum and its inversion. J. Geophys. Res. 1991, 96, 10713-10729. [CrossRef]

20. Hasselmann, S.; Bruning, C.; Hasselmann, K.; Heimbach, P. An improved algorithm for the retrieval of ocean wave spectra from synthetic aperture radar image spectra. J. Geophys. Res. 1996, 101, 16615-16629. [CrossRef]

21. Donelan, M.; Hamilton, J.; Hui, W.H. Directional spectra of wind generated waves. Philos. R. Soc. 1995, 315, 509-562. [CrossRef]

22. Mastenbroek, C.; De Valk, C.F. A semiparametric algorithm to retrieve ocean wave spectra from synthetic aperture radar. J. Geophys. Res. 2000, 105, 3497-3516. [CrossRef]

23. Engen, G.; Johnsen, H. SAR-ocean wave inversion using image cross spectra. IEEE Trans. Geosci. Remote Sens. 1995, 33, 1047-1056. [CrossRef]

24. Keller, J.B. Gravity waves on ice-covered water. J. Geophys. Res. 1998, 103, 7663-7669. [CrossRef]

25. Worby, A.P. Observing Antarctic Sea Ice: A Practical Guide for Conducting Sea Ice Observations from Vessels Operating in the Antarctic Pack Ice; A CD-ROM Produced for the Antarctic Sea Ice Processes and Climate (ASPeCt) Program of the Scientific Committee for Antarctic Research (SCAR) Global Change (GLOCHANT) Program: Tasmania, Australia, 1999.

26. Thorpe, S.A. Langmuir circulation. Annu. Rev. Fluid Mech. 2004, 36, 55-79. [CrossRef]

27. Plueddemann, A.J.; Smith, J.A.; Farmer, D.M.; Weller, R.A.; Crawford, W.R.; Pinkel, R.; Vagle, S.; Gnanadeskian, A. Structure and variability of Langmuir circulation during the surface waves processes program. J. Geophys. Res. 1996, 101, 3525-3543. [CrossRef]

28. Morelli, S.; Parmiggiani, F. Wind over Terra Nova Bay (Antarctica) during a polynya event: Eta model simulations and satellite microwave observations. Eur. Phys. J. Plus 2013, 128, 135. [CrossRef]

29. Hollands, T.; Dierking, W. Dynamics of the Terra Nova Bay Polynya: The potential of multi-sensor satellite observations. Remote Sens. Environ. 2016, 187, 30-48. [CrossRef]

30. Roach, L.A.; Smith, M.M.; Dean, S.M. Quantifying growth of pancake sea ice floes using images from drifting buoys. J. Geophys. Res. Oceans 2018, 123, 2851-2866. [CrossRef]

31. Wadhams, P.; Holt, B. Waves in Frazil and Pancake Ice and Their Detection in Seasat Synthetic Aperture Radar Imagery. J. Geophys. Res. 1991, 96, 8835-8852. [CrossRef]

(C) 2019 by the authors. Licensee MDPI, Basel, Switzerland. This article is an open access article distributed under the terms and conditions of the Creative Commons Attribution (CC BY) license (http://creativecommons.org/licenses/by/4.0/). 